\title{
Zoning Regional Banking Sector as a Factor of Its Financial Stability
}

\author{
Klaas J.A.", Mavlina A.G. \\ Institute of Economics and Finance, Kazan Federal University, Russia
}

Copyright $\bigcirc 2016$ by authors, all rights reserved. Authors agree that this article remains permanently open access under the terms of the Creative Commons Attribution License 4.0 International License

\begin{abstract}
This article deals with the problem of assessment of commercial banks financial stability. In the framework of the article are approved methodology for assessing financial stability on the example of regional banks of the Republic of Tatarstan, as well as conclusions about the sustainability of the regional banking system in a worsening debt crisis and the increasing volatility in global financial markets are drawn. Economic and statistical techniques were used: grouping, ranking, a probabilistic assessment, analysis of volume indicators. We have produced results, indicating that there are problems in the activities of the regional banks that undermine stability of the regional banking system and also Russian banking sector as a whole.
\end{abstract}

Keywords Financial Stability, Commercial Bank, Zoning, Assessment Methodology, The Regional Banking System

\section{Introduction}

At the present stage of development in the global financial markets remains a high level of instability that is associated with both economic and political risks. Against the backdrop of the global economic slowdown the authorities of the countries and leading central banks take action to support economic growth and the fight against the debt crisis, international organizations working on measures to strengthen the financial system $[4,5]$. The Russian economy strong enough exposes to the impact of slowing global economic growth, worsening debt crisis and the increasing volatility in global financial markets. Because of the specific structure of the Russian economy, and a large share of oil and gas revenues in total export earnings, drop in energy prices, the outflow of capital on the presence of a high proportion of non-residents in the stock market and, as a consequence, the weakening of the balance of payments are the most significant factors in the deterioration of the situation in the Russian financial sector [1]. First and foremost, this consequences of this events concerns the Russian banking system, which the most important part are regional banks that perform an important social function, meeting the needs of the population and enterprises in banking services, smoothing significant disproportions in the provision of banking services in the regions of Russia with a total backlog of the indicator by global standards [8]. In this regard, the assessment of the financial sustainability of the regional banks in relation to external shocks and crises is rather important [7].

Currently, there are a great variety of methods of commercial banks financial stability assessment, allows to make high-quality and reasonably accurate conclusions. The problem of assessment of commercial banks financial stability in I.V. Vishnyakov, Yu.Yu. Rusanov, Z.A. Timofeyeva, G.G. Fetisov, O. I. Lavrushin, G. N. Scherbakova, V.V. Ivanov, S.M. Ilyasov, E.A. Tarkhanova and others works is investigated [6]. However in the field of stability of banks there are still many unsolved problems both theoretical and practical. The analysis of the works of these authors is showed that researches of banks financial stability are in an incomplete state: publications are devoted mainly to the description of practical aspects of the problem, individual methods of the analysis of banks financial stability [11].

To solve the problem by evaluating the financial stability of regional banks in relation to external shocks, financial stability of 21 regional banks of the Republic of Tatarstan was analyzed.

\section{Object of Investigation}

The banking sector of the Republic of Tatarstan is one of the most developed in Russia, conceding only to Moscow and St. Petersburg in term of number of banks. In the republic there was a good system of small, medium and large banks. Local independent banks are dominated. There are 21 local independent banks, which is about $60 \%$ of all commercial banks operating in the region. The ratio of small, medium and large independent banks is clearly shown in table 1 . Under article names of the banks alphabetically are 
replaced by symbols. A characteristic feature of the republic banking sector is working closely with local power structures in support of regional business. Historically, even in the nineties the republic's leadership has paid considerable attention to development of local banking. As a result, now the republic banking system has become one of the most powerful in the country. It is an effective interaction between the two institutions - government and business - helped banks of the republic to become the leader of the market and maintain their best quality, even in tough competition among themselves and with the branches of the largest banks in the country. In addition, none region of the Volga region can boast of such a degree of involvement of the banking business in the regional programs [2].

Table 1. The ratio of small, medium and large banks of the Republic of Tatarstan [12]

\begin{tabular}{|c|c|c|}
\hline Large banks & Medium banks & Small banks \\
\hline Bank 4 & Bank 1 & Bank 2 \\
\hline \multirow[t]{11}{*}{ Bank 20} & Bank 5 & Bank 3 \\
\hline & Bank 8 & Bank 6 \\
\hline & Bank 10 & Bank 7 \\
\hline & Bank 12 & Bank 9 \\
\hline & Bank 16 & Bank 11 \\
\hline & Bank 21 & Bank 13 \\
\hline & & Bank 14 \\
\hline & & Bank 15 \\
\hline & & Bank 17 \\
\hline & & Bank 18 \\
\hline & & Bank 19 \\
\hline
\end{tabular}

\section{Methodology}

To assess the financial stability of regional banks of Tatarstan we were tested method of rating agency «Expert».

The approach used in the rating of the rating agency «Expert» is a bit different from other Russian techniques. This technique is an attempt to create a comprehensive comparative ranking. Procedure consists of two main parts. The first (static) part involves the comparison of the banks in the coordinate system of «profitability-reliability» [3]. The rate of profitability and an indicator of the reliability are carried out on the following formula:

$$
\begin{aligned}
& \text { Rate of profitability }=\frac{\text { balance sheet profit }}{\text { net assets }} \\
& \text { Indicator of the reliability }=\frac{\text { own capital }}{\text { borrowed funds }}
\end{aligned}
$$

The results of two-criterion analysis of the current condition of the banks are put on a plane with the $\mathrm{x}$-ax corresponds to the index of reliability, and the $y$-ax corresponds to the indicator of profitability, as a result the coordinate space is divided into four segments. The coordinate system of «profitability-reliability» is presented in figure 1.

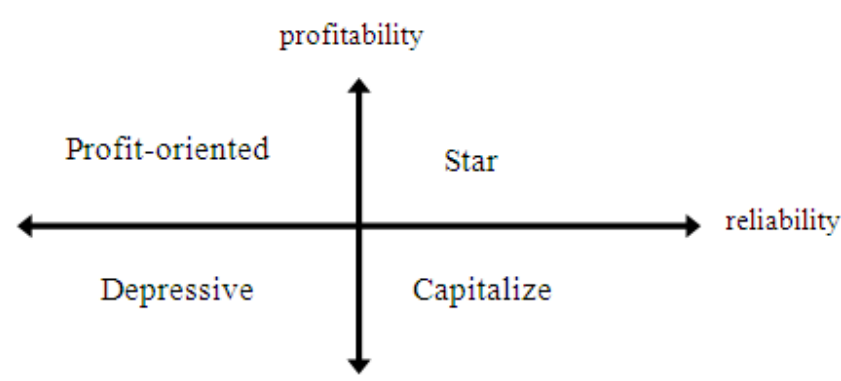

Figure 1. The coordinate system of «profitability-reliability» [10]

The second part is to analyze the dynamics of changes in the parameters of profitability and reliability over time.

\section{Results}

According to the methodology of rating agency «Expert» analyzed the financial stability of 21 regional banks of the republic. The results of two-criterion analysis of the current status of the rating agency «Expert» procedure are shown in figures 2-4. As we seen in figures 2-4, the majority of the regional banks are in the zone of «depressed» banks whose reliability is below average, and thus there is low profitability of use of significant amounts of funds and the category «profit-oriented» banks with a highly profitable use of relatively large amounts of funds. Approximately the same numbers of banks are in the second and third zone, namely in the segment «capitalized» banks, characterized by high capital adequacy ratio at a low profitability of use of resources and in the zone of «star» banks, which profitability and reliability is above average. 


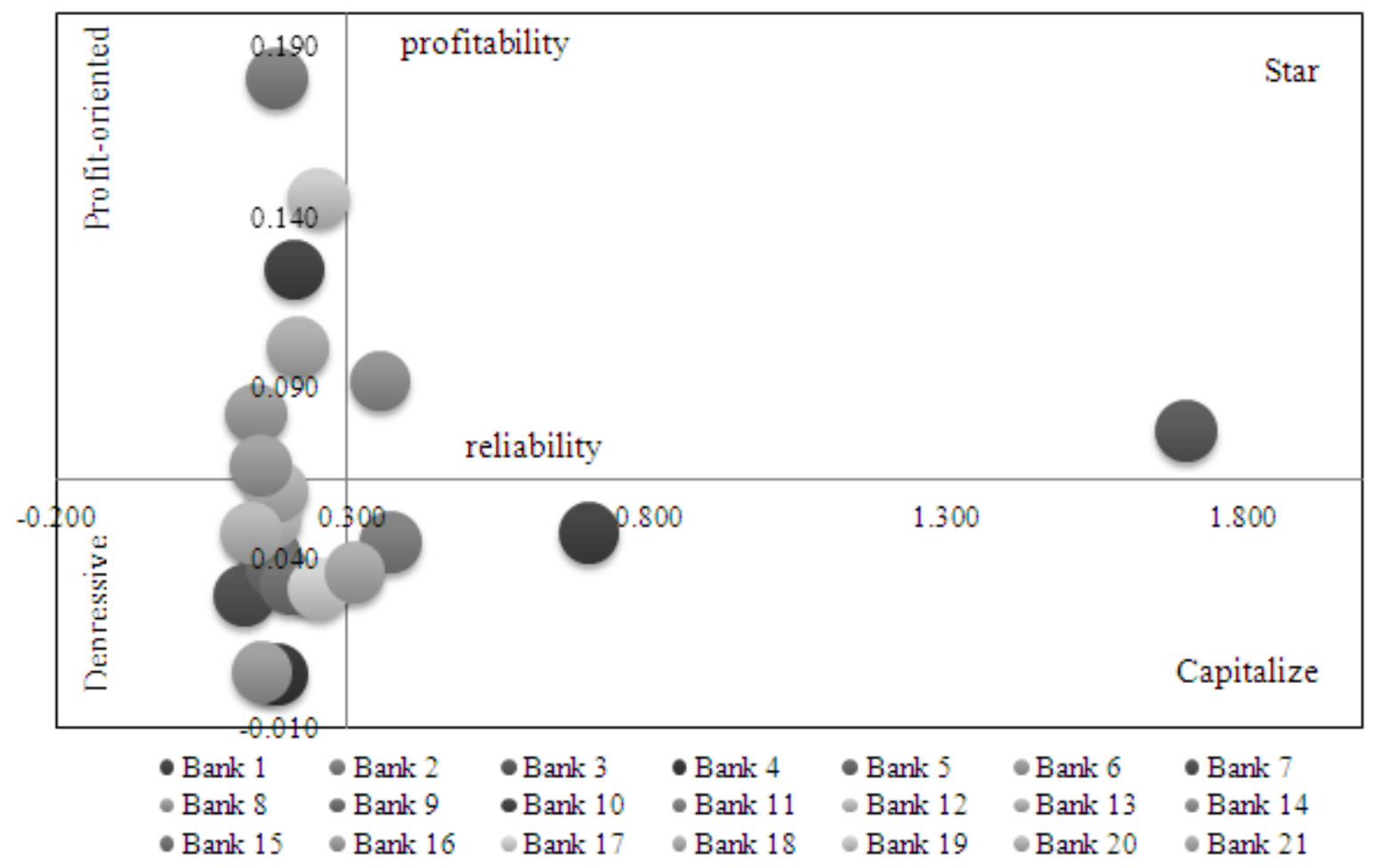

Figure 2. Location of regional banks in the coordinate system of «profitability- reliability» in 2011 [12]

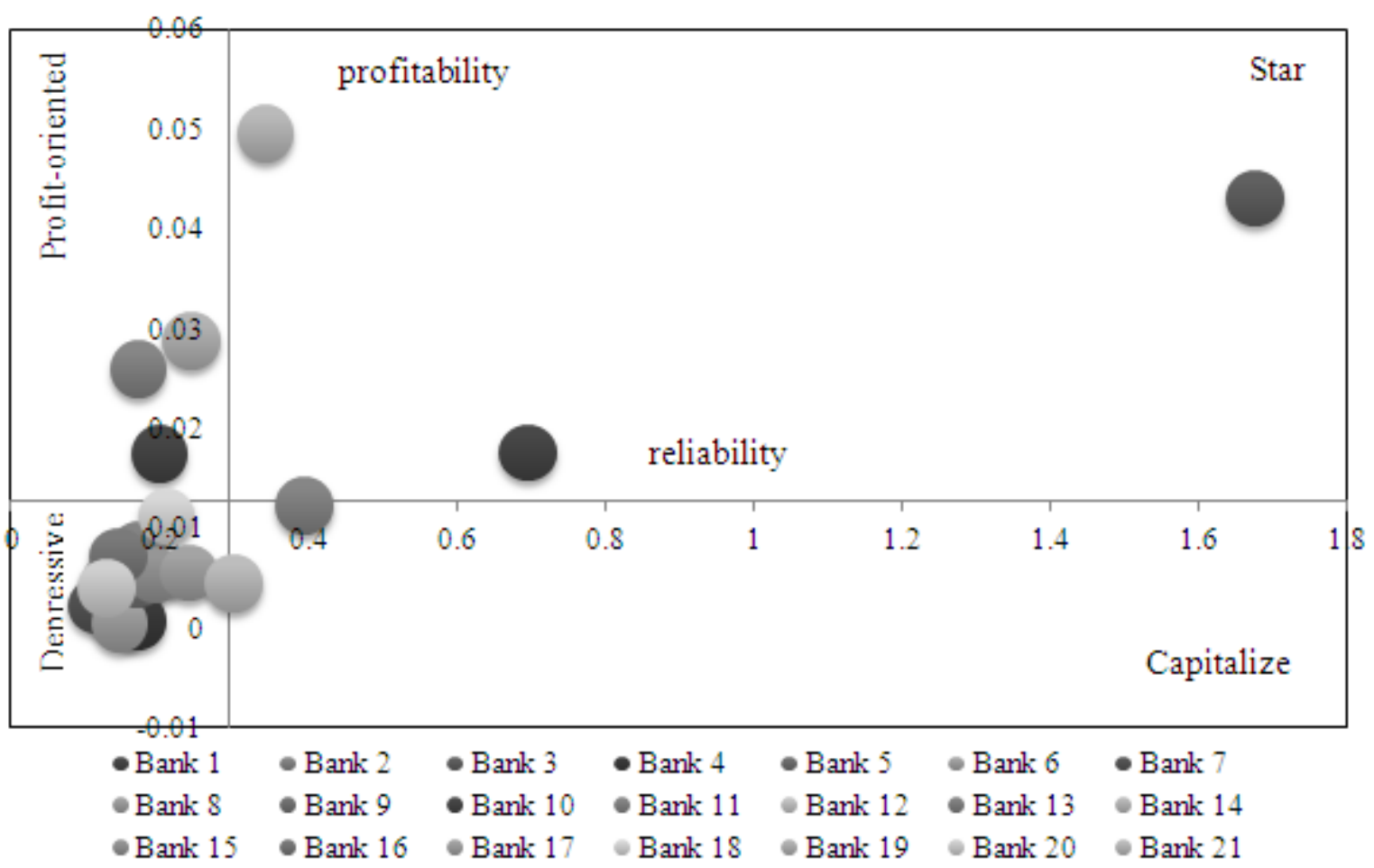

Figure 3. Location of regional banks in the coordinate system of «profitability- reliability» in 2012 [12] 


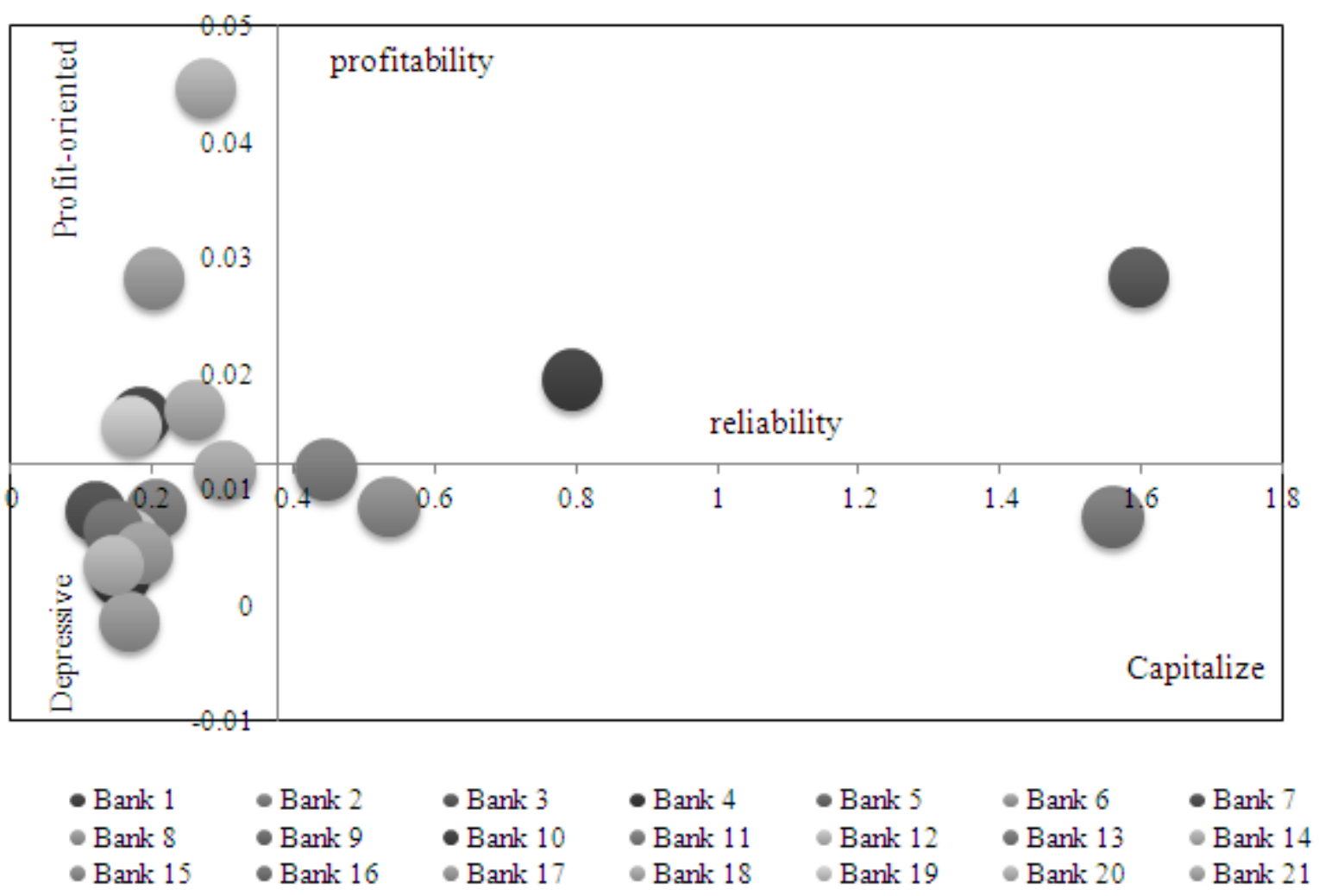

Figure 4. Location of regional banks in the coordinate system of «profitability- reliability» in 2013 [12]

The presence of approximately $50 \%$ of the «depressed» banks in the regional banking system does not allow drawing conclusions about its sustainability. One of the main factors that caused the dominance of «depressed» banks is the low profitability of active operations held by banks, which in 2013 year varies for the «depressed» banks from $0,25 \%$ to $0,83 \%$, while for the «star» and «profit-oriented» banks the level of profitability is $1,54 \%$ and $4,46 \%$, respectively. These significant differences in profitability associated with the structure both outstanding and borrowed funds. In this case, certain features of both the location and bringing in «depressed» banks are not available.

Reliability index of the bank which determines the degree of coverage of funds equity is no less important. The value of this index in 2013 is in the range of $12 \%$ to $20,5 \%$ for the «depressed» banks, due to their substantial undercapitalisation, given the fact that the profit is one of the most reliable sources of capital expansion, and «depressed» banks are characterized by low profitability, the current situation of data banks could worsen in the medium term [9].

At the same time, «capitalized» banks in front tend to group «depressed» in this context it is important to make efforts to prevent this transition, and the «star» banks to use every opportunity to maintain their positions.

Thus, the current situation indicates a need for a stabilizing measures to help to improve the sustainability of commercial banks and ultimately the formation of a stable regional banking system of the Republic of Tatarstan, consisting of «star» and «profit-oriented» banks, which currently accounts are only $33 \%$ of analyzed regional banks.

\section{Summary and Conclusion}

Summarizing the results of analysis of financial stability of regional banks we can make up a conclusion about relative instability of the banking sector of the Republic of Tatarstan. There were problems in the regional banks that undermine stability of the regional banking system, which in the case of a crisis will lead to a loss of stability of Russian banking sector. In this case, the distinguishing feature is that the greatest resistance to the negative factors has small banks, while large banks in the event of destabilizing tendencies may eventually lose its stability. In this regard, first of all large and medium-sized banks need to develop a system of measures aimed at ensuring financial stability, as well as the timely prevention of destructive tendencies, which helps to maintain not only their sustainability, but also the regional banking system as a whole.

\section{REFERENCES}

[1] Aiyar, S. From financial crisis to Great Recession: The role of globalized banks // American Economic Review, 102 (3), 2012. pp. 225-230.

[2] Bagautdinova, N.G., Sabitov, N.H., Salakhov, B.R., 
Shakhnina, I.Z. Regional banks in the system of government regulation of economy // Mediterranean Journal of Social Sciences, 5 (12), 2014. pp. 39-42

[3] Brauers, W.K.M., Ginevičius, R., Podviezko, A. Development of a methodology of evaluation of financial stability of commercial banks // Panoeconomicus (3), 2014. pp. 349-367

[4] De Haas, R., Van Lelyveld, I. Multinational banks and the global financial crisis: Weathering the perfect storm? // Journal of Money, Credit and Banking (46), 2014, pp. 333-364.

[5] Gómez, F. Failed bank takeovers and financial stability // Journal of Financial Stability (16), 2015, pp. 45-58.

[6] Klaas, J., Vagizova, V. Tools for assessing and forecasting financial stability of the commercial bank under conditions of instability // Investment Management and Financial Innovations (4), 2014. pp. 157-163.

[7] Kundukchyan, R.M., Gaizatullin, R.R., Zappartova, Z.N. Russian financial system and integration processes // Mediterranean Journal of Social Sciences (18 SPEC. ISSUE), 2014. pp. $67-72$
[8] Naveh, M.H., Torosyan, T., Jalaee, S.A. Regional economic integration and its effects on economic growth and economic welfare // World Applied Sciences Journal, 17 (10), 2012. pp. 1349-1355

[9] Fungáčová, Z., Jakubík, P. Bank stress tests as an information device for emerging markets: The case of Russia // Finance a Uver - Czech Journal of Economics and Finance, 63 (1), 2013. pp. 87-105.

[10] Vagizova, V., Klaas, J., Batorshyna, A. Financial stability assessment of regional banking sector under modern conditions by means of operating procedures of its determination // Investment Management and Financial Innovations, 10 (3), 2013. pp. 89-97.

[11] Webb Cooper, E. Monitoring and governance of private banks //Quarterly Review of Economics and Finance, 49 (2), 2009. pp. 253-264.

[12] Bank of Russia [electronic resource]: Information on Credit Institutions. Official site of the Bank of Russia, 2014. http://www.cbr.ru. 